\title{
Factors Contributing Towards Malnutrition Among Under Five Indigenous Children: A Systematic Review
}

\author{
Liyanatul Najwa Zakaria, Halimatus Sakdiah Minhat, Nor Afiah Mohd Zulkefli, \\ Anisah Baharom and Norliza Ahmad
}

Department of Community Health, University of Putra Malaysia (UPM), 43400 Seri Kembangan, Serdang, Malaysia; liyanatul.zakaria@gmail.com, halimatus@upm.edu.my,norafiah@upm.edu.my,

b_anisah@upm.edu.my, lizaahmad@upm.edu.my

\begin{abstract}
Objectives: To identify and synthesize the evidences regarding factors contributing towards malnutrition among fewer than five indigenous children. Methodology: A systematic review was conducted using electronic databases by searching published articles earliest from January 2000 to April 2017 using five different data bases including MEDLINE, PubMed, Scopus, Proquest and CINAHL. Literatures that provide information on factors contributing towards malnutrition among fewer than five indigenous children according to type of malnutrition (stunting, wasting and underweight) were included. A narrative synthesis was used. Findings: Nine studies were assessed and reviewed in the final stage. This review found that malnutrition among fewer than five indigenous populations is a multifactorial problem and that different domain play in the pathway. These mainly include socioeconomic status, parental factor, and child factor, hygiene and child morbidity as the most common and significant factors contributing towards malnutrition among under five indigenous children. Novelty/ Improvement: Identification of appropriate and relevant factors contributing towards malnutrition problem among fewer than five indigenous populations is important to develop a well-planned and ensuring the effectiveness of health intervention.
\end{abstract}

Keywords: Aborigin, Child, Factors, Indigenous, Malnutrition, Under Five, Under Nutrition

\section{Introduction}

Malnutrition remains as an important public health issues in both developed and developing countries affecting wide range of age in a population significantly affecting children under five. It is caused by a complex, multidimensional and interrelated condition which is largely contributed by a set of socio demographics, economic, environmental and biological factors with high prevalence rate among children under unfavourable conditions ${ }^{1}$. Globally, statistics in 2017 shows that about 159 million and 50 million children under five were stunted and wasted causing more than one third of all child deaths which is translated into the unnecessary loss of about 3 million young lives a year ${ }^{2}$.

Childhood malnutrition persists as a major health problem among indigenous groups. Studies have shown that indigenous children have higher probabilities of suffering from malnutrition as compared to nonindigenous group ${ }^{3-4}$. They are identified as the most vulnerable group with poorer health, greater likelihood of experiencing disability, reduced quality of life and ultimately die younger than their non-indigenous counterpart ${ }^{5}$.

Indigenous group is known as a unique population practicing unique traditions; they retain social, cultural,

${ }^{*}$ Author for correspondence 
economic and political characteristics that are distinct from those of the dominant societies in which they live ${ }^{6}$. Factors contributing towards child malnutrition might not be similar as compared to the non-indigenous group which requires specific health intervention. Thus, this review aims to identify and synthesize evidence about the factors contributing towards malnutrition among under five indigenous children. This is essential as a guidance to understand methods and health interventions used to be applied accordingly.

\section{Methods}

\subsection{Study Search}

A systematic review was conducted by searching published articles written in English from different data bases including MEDLINE, PubMed, Scopus, Proquest and CINAHL. The keywords searched from titles and abstracts were screened and assessed for relevance.

The full text of each of the relevant articles was then reviewed and studies were excluded if they did not provide data on the determinants of malnutrition among indigenous group. The keywords used to search the articles include:

1. Malnutrition OR undernutrition OR underweight OR stunting OR wasting AND;

2. Orang Asli OR aborigine OR indigenous OR Orang Asli OR tribe AND;

3. Under five OR children OR child AND; and

4. Causes OR determinants OR associated factors OR risk factors OR predictor.

\subsection{Inclusion Criteria}

The inclusion criteria of articles to be included in this review include the following:

1. Articles published in English languages only with full text article from published articles in citation indexed journals and peer reviewed journals,

2. Any studies that include indigenous group,

3. The cut off point for age among the indigenous children participated in the study must be less than 5 years old,

4. Using WHO Child Growth Standards 2006 to determine malnutrition status of indigenous children, and
5. Articles publishes from January 2000 to May 2017.

Initially, the search was limited to the past ten years; however, due to the scarcity of good articles, the date range was expanded from January 2000 to the recent year.

\subsection{Study Outcome}

The primary outcome of this review was the factors associated with malnutrition among under five indigenous children. Under five malnutrition was determined according to WHO Child Growth Standards 2006 by measuring weight and height of the children. According to the WHO standard, any children with Height for-Age (HAZ) or Weight-for Age (WAZ) or Weight-forHeight (WHZ) below -2 SD are categorised as stunted, underweight and wasted, respectively by taking age and sex into consideration. Factors contributing towards malnutrition among under five indigenous children is determined according to statistical analysis of the studies by looking at Adjusted Odd Ratio (AOR), Odds Ratio $(\mathrm{OR})$, Prevalence Ratio (PR) and significant $\mathrm{p}$ value of $<0.05$ and no exclusions were made for type of statistical approach.

\subsection{Data Extraction}

All data were extracted independently by a single reviewer. Data were extracted from the selected articles to a standardized table by one of the investigators containing information such as title, authors, country where the study was performed, publication year, age of participants, sample size, instruments used to determine factors or predictors associated with malnutrition, number of weight and height measurement and type of measuring device used were extracted. In the tables, results of studies are reported only for the outcome measures interest. Any uncertainties were resolved by discussion with one colleague and during disagreement the final decision was made based on the opinion of senior experts.

In the primary search, 929 records were found. After the initial search, 45 duplicated articles were removed. Of the 884 records, 76 articles with full text and english language were selected excluding irrelevant abtracts and titles as well as record from conferences, congresses, editorial, commentaries and news. These articles were then assesed for eligibility criteria, articles which include more than 5 years old children, involving non indigenous group as part of respondents and not using WHO Child 
Growth Standards 2006 to measure growth status were excluded. In the final section, 9 articles were considered relevant to be included in the systematic review.

\section{Results}

In the initial search 929 articles were identified and 9 studies $(n=35,520)$ were deemed eligible in the final stage. Figure 1 shows the flow chart of the selection of studies. Based on STROBE checklist the quality scores and criteria list for the methodological assessment of the reviewed articles ranges from 14 to 20 as shown in Table 1 . The items which were performed poorly by the studies were those related to explain study size, efforts to address any potential bias, give reasons for non-participation at each stage and generalizability and source of funding.

\subsection{Study Characteristics}

Information regarding selected studies is shown in Table 2. Most of the selected studies were cross sectional design except for one mixed method study design. There were 3 studies conducted in India ${ }^{7-9}$, followed by 2 studies in Guatemala ${ }^{10,11}$ and Brazil ${ }^{12,}, \underline{13}$ and 1 study from Mexico ${ }^{14}$ and Malaysia ${ }^{15}$. The studies included participants ranging

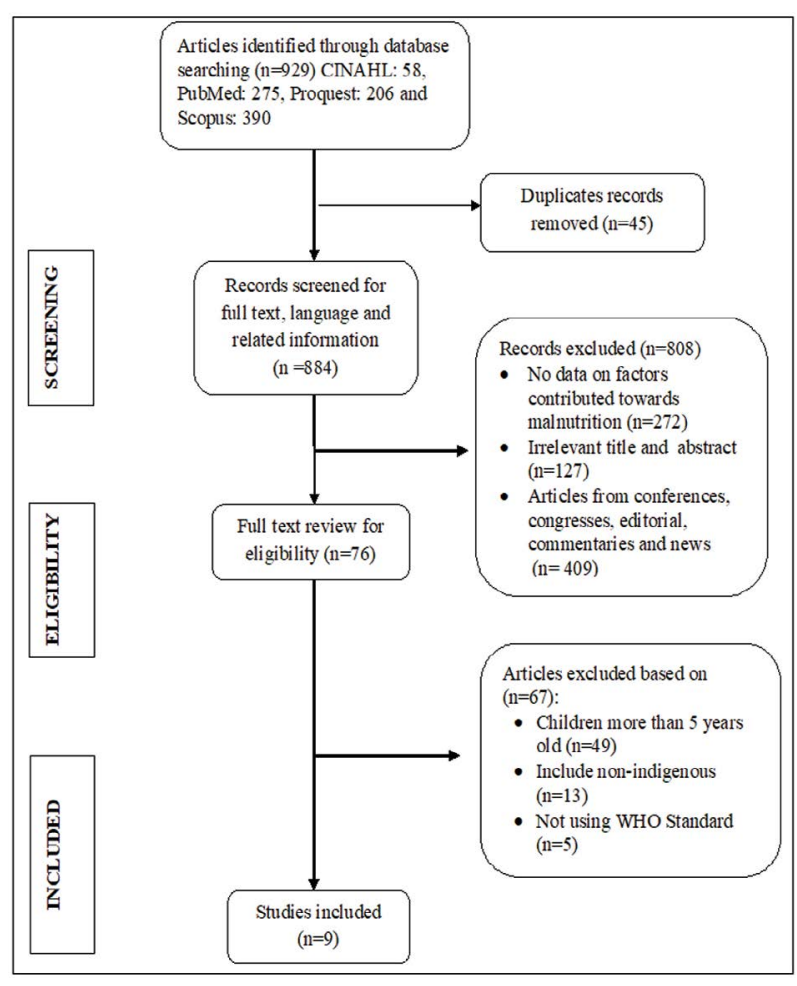

Figure 1. Diagrammatic flow of studies selection. from 0 to 59 months old indigenous children. However, the studies were done with different standardized age. Six numbers of studies $, 2,10,12-14$ were done with participant with age between 0-59 months old and two other studies ${ }^{10-11}$ involved participants aged less than 3 years old. Meanwhile, there was only one study recruiting participant's age of less than 2 years of old $\frac{8}{}$. Numbers of fewer than five children's sample size of the studies ranging from 92 to 14,587. The study with the largest sample size was carried out in India by which covering almost twothirds of the total tribal population ${ }^{7}$. Most of the studies were focusing only on one type of malnutrition especially on stunting to determine malnutrition status through anthropometric measurement. There are only two studies include all 3 types of malnutrition status to categorise the children (stunting, wasting and underweight) $\underline{\underline{1}}, \underline{15}$.

\subsection{Anthropometric Measurement}

All 9 studies included in the review used WHO criteria for the classification of malnutrition. There were only 4 studies mentioned regarding type of anthropometric instruments used to measure height and weight of the children $-\underline{8-10}$. There are only one study reported taking an average value of two readings to minimize risk of measurement bias ${ }^{12}$. In order to determine factors contributing towards malnutrition among under five indigenous children, 5 studies used questionnaire include one study which combine with observational checklist ${ }^{7-10}, \underline{12}, \underline{13}$.

Meanwhile, 2 of other studies used secondary data from national survey-11 ${ }^{9-1}$ and 1 study used anthropometric measurement only for their data collection 10

\subsection{Factors Contributing Towards Malnutrition Among Under Five Indigenous Population}

Factors contributed towards malnutrition among less than five indigenous populations are listed in Table 3.

\subsection{Socioeconomic Status}

Socioeconomic status was one of the factors contributed towards child malnutrition among indigenous population. Based on an assessment of economic conditions owing to high proportion families with no formal income $e^{\frac{16}{6}}$ a study found that household good index was inversely proportional to prevalence of malnutrition among 
Table 1. Quality scores and criteria list for the methodological assessment of reviewed articles.

\begin{tabular}{|c|c|c|c|c|c|c|c|c|c|c|c|c|c|c|c|c|c|c|c|c|c|c|c|}
\hline \multirow{2}{*}{ Study } & \multicolumn{22}{|c|}{ Scores on STROBE statement } & \multirow[t]{2}{*}{ Total } \\
\hline & - & N & $m$ & H & in & 6 & $\Lambda$ & $\infty$ & $a$ & 음 & $\Xi$ & I & 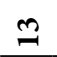 & $\Xi$ & 10 & $\stackrel{0}{2}$ & 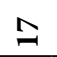 & $\stackrel{\infty}{=}$ & 2 & 오 & $\bar{\lambda}$ & ก & \\
\hline $\begin{array}{l}\text { Solomons et. al. } \\
(2013)\end{array}$ & I & I & - & - & I & / & l & I & - & - & - & - & - & - & / & - & - & - & - & - & - & - & 7 \\
\hline $\begin{array}{l}\text { Tumilowicz et. al. } \\
\text { (2015) } \\
\text { Sanchez-Perez et al } \\
(2007)\end{array}$ & l & l & - & - & l & l & / & l & - & l & / & - & - & / & / & - & / & l & I & / & - & - & 14 \\
\hline Arajou et. al. (2016) & l & I & / & / & - & - & - & I & - & - & l & - & - & I & l & I & - & l & - & / & I & l & 19 \\
\hline Saxton et. al. (2016) & I & I & / & / & I & I & l & I & l & - & l & / & / & I & I & / & l & I & / & / & - & - & 17 \\
\hline $\begin{array}{l}\text { Dinacahandra et.al. } \\
\text { (2015) }\end{array}$ & l & l & / & / & l & I & / & / & - & - & / & / & - & l & / & / & / & l & / & / & - & - & 17 \\
\hline Horta et. al. (2013) & l & l & / & / & l & l & l & l & l & / & l & / & l & l & / & l & l & l & l & - & / & - & 20 \\
\hline $\begin{array}{l}\text { Meshram et. al. } \\
(2012)\end{array}$ & l & I & - & I & I & / & / & / & I & I & I & I & - & I & I & I & I & I & - & I & - & - & 17 \\
\hline $\begin{array}{l}\text { Shashikala et. al. } \\
\text { (2005) }\end{array}$ & - & I & - & I & I & I & I & I & I & I & I & I & - & I & I & - & I & I & I & I & - & - & 16 \\
\hline
\end{tabular}

indigenous children ${ }^{-}$. This finding was also supported by another three studies conducted India and Brazil which revealed that children living in lower household wealth index, living in rural area and living in houses made of walking palm are more likely to be malnourished $\$ 12$.

Household environmental health risk index was found to be significantly associated with wasting among indigenous children'. It represents a reasonable aggregate measure that can be used to compare environmental risks for households in a given community include source of drinking water, type of toilet facility, cooking fuel used and type of house. It was reported that children with medium and low household health risk were significant and positively related with wasting as compared to high household health risk index ${ }^{14}$. In addition, geographical factor such as region of living and living in rural area was significantly contributed towards stunting as reported $\mathrm{d}^{14,17}$.

\subsection{Parental Factor}

Evidence shows that children with younger mother reported to be more likely to be malnourished as compared to older mother $\stackrel{\underline{13}}{ }$. Furthermore, two studies reported that mothers with low level of education are more likely to be malnourished as compared to those with higher maternal education ${ }^{7,13}$.
Studies also found that both maternal literacy status and literacy household head play a significant role in determining malnutrition ${ }^{9} \underline{13}$. Additionally, biological factor such as maternal height and severe maternal anemia were also found to be significant factors towards malnutrition $\underline{10,12-13}$. On the other hand, level of mass media exposure among mothers also determine children nutritional status whereby mothers with low, medium and high level of mass media exposure were less subjected to wasted child as compared to none media exposure ${ }^{9}$.

\subsection{Child Factor}

Several studies have revealed that children factor also important in considering factor contributes toward child malnutrition which includes child's age, gender, low birth weight and later birth order. Three studies concluded that prevalence of malnutrition among children between 1-5 years old is higher as compared to children between $0-1$ years old $7 \underline{13}, \underline{14}$. This finding is contrast with a study reported which reported that children aged less than 24 months are more likely to be malnourished. Evidences have shown that boys are more likely to be malnourished as compared to girls ${ }^{7} \underline{11}, \underline{13}$. In addition, studies ${ }^{13}$ found that children with birtweight $<2.5 \mathrm{~kg}$ were more at risk to be malnourished as compared to children with birthweight $>3.5 \mathrm{~kg}$. In terms of birth order, study reported that 
Table 2. Summary of systematic review of the determinants of malnutrition among under five indigenous children from January 2000- April 2017

\begin{tabular}{|c|c|c|c|c|c|c|}
\hline \multirow[b]{2}{*}{ Sl. No. } & \multirow{2}{*}{$\begin{array}{l}\text { Author/year of } \\
\text { publication/ } \\
\text { study design/ } \\
\text { sample size (N) }\end{array}$} & \multirow[b]{2}{*}{$\begin{array}{c}\text { Age of } \\
\text { participants } \\
\text { (months) }\end{array}$} & \multicolumn{2}{|c|}{ Instruments used } & \multirow[b]{2}{*}{$\begin{array}{l}\text { Type of } \\
\text { malnutrition }\end{array}$} & \multirow[b]{2}{*}{ Results } \\
\hline & & & $\begin{array}{c}\text { Type/frequency of } \\
\text { anthropometric } \\
\text { measurement }\end{array}$ & $\begin{array}{l}\text { Factors } \\
\text { contributing } \\
\text { towards } \\
\text { malnutrition }\end{array}$ & & \\
\hline 1. & $\begin{array}{l}\text { Araujo et al, } \\
2016 \text { (Brazil) } \\
\text { Cross sectional } \\
(\mathrm{N}=478)\end{array}$ & $0-59$ & $\begin{array}{l}\text { Not mentioned/ } \\
\text { average } 2 \text { values }\end{array}$ & $\begin{array}{l}\text { Structured } \\
\text { questionnaire }\end{array}$ & Stunting & $\begin{array}{l}\text { Factors contributed towards stunting: } \\
\text { child age of }>24 \text { months (APR } 1.4 \text {, } \\
95 \% \text { CI } 1.1-1.8 \text { ) living in rural area (PR } \\
=1.6 \text {; } 95 \% \text { CI } 1.2-2.1 \text { ); household } \\
\text { made of walking palm or shanty } \\
\text { (APR 1.6. 95\%CI } 1.1-2.4 \text { ), } 1^{\text {st }} \text { tertile } \\
\text { of household wealth index (APR = } \\
1.6 \text {; } 95 \% \text { CI } 1.1-2.4 \text { ); maternal height } \\
\text { less than or equal to } 146.4 \mathrm{~cm} \text { (APR } \\
=3.1 \text {; } 95 \% \mathrm{CI} 1.9-5.0 \text { ); history of } \\
\text { introduction of cow's milk before } 30 \\
\text { days of age (APR }=1.4 ; 95 \% \text { CI } 1.0- \\
1.8 \text { ) and up to date with vaccination } \\
\text { schedule (APR } 0.7,95 \% \text { CI } 0.5-0.9 \text { ) }\end{array}$ \\
\hline 2. & $\begin{array}{l}\text { Solomons et al, } \\
2013 \\
\text { (Guatemala) } \\
\text { Cross ectional } \\
(\mathrm{N}=306)\end{array}$ & $6-59$ & $\begin{array}{l}\text { SECA } 2010 \\
\text { infantometer/Not } \\
\text { mentioned }\end{array}$ & $\begin{array}{l}\text { Wall stadio- } \\
\text { meter } \\
\text { (Maternal } \\
\text { height) }\end{array}$ & Stunting & $\begin{array}{l}\text { Maternal height explained } 3 \% \text { of } \\
\text { the variability in stunting }(r=0.171 \text {, } \\
\mathrm{r} 2=0.029 \text {, } \\
\mathrm{P}=0.003) \text {. }\end{array}$ \\
\hline 3. & $\begin{array}{l}\text { Saxton et. al., } \\
2016 \text { (India) } \\
\text { Cross sectional } \\
(\mathrm{N}=1227)\end{array}$ & $6-24$ & $\begin{array}{l}\text { SECA } 874 \\
\text { weighing scales } \\
\text { with taring button, } \\
\text { Leicester height } \\
\text { measures and } \\
\text { SECA measuring } \\
\text { mat/ Not } \\
\text { mentioned }\end{array}$ & $\begin{array}{l}\text { Guided } \\
\text { Questionnaire }\end{array}$ & Stunting & $\begin{array}{l}\text { Fourth born (AOR - } 0.379,95 \% \\
-0.651--0.107) \text { and repeated diarrhoeal } \\
\text { infection (AOR - } 0.233,95 \% \text { CI } 0.387- \\
0.079 \text { ) were among the significant } \\
\text { risk factor contribute towards stunting. } \\
\text { Meanwhile, factors such as cooking } \\
\text { outdoors (AOR } 0.663,95 \% \text { CI } 0.348- \\
0.977 \text { ), using handwashing agent } \\
\text { such as ash/soap (AOR } 0.317,95 \% \mathrm{CI} \\
0.106-0.528 \text { ) and male (AOR } 0.271 \text {, } \\
\text { 95\% CI } 0.133-0.408 \text { ) were among the } \\
\text { significant protective factors towards } \\
\text { stunting. }\end{array}$ \\
\hline 4. & $\begin{array}{l}\text { Singh et al, } 2015 \\
\text { (India) } \\
\text { Cross sectional } \\
(\mathrm{N}=7574)\end{array}$ & $0-59$ & $\begin{array}{l}\text { Not mentioned/ } \\
\text { Not mentioned }\end{array}$ & $\begin{array}{l}\text { Secondary } \\
\text { data (Census } \\
\text { of India) }\end{array}$ & Wasting & $\begin{array}{l}\text { Significant factors for wasting include } \\
\text { scheduled caste }(\mathrm{r}=0.22, \quad \mathrm{p}=0.04), \\
\text { literate household heads }(\mathrm{r}=0.09, \\
\mathrm{p}=0.04), \text { receive measles vaccination } \\
(\mathrm{r}=0.09, \mathrm{p}=0.04), \text { high household } \\
\text { health risk }(\mathrm{r}=0.16, \mathrm{p}=0.04), \text { medium } \\
\text { household health risk }(\mathrm{r}=0.22 \mathrm{p}=0.06), \\
\text { age of mother between } 15-19(\mathrm{r}=0.18, \\
\mathrm{p}=0.08) \text {, low, medium and high level } \\
\text { of exposure to mass media }(\mathrm{r}=0.16, \\
\mathrm{p}=0.05 ; \quad \mathrm{r}=0.22, \mathrm{p}=0.66 ; \quad \mathrm{r}=0.18, \\
\mathrm{p}=0.07) \text { and colostrum given }(\mathrm{r}=0.09, \\
\mathrm{p}<0.04)\end{array}$ \\
\hline
\end{tabular}


5. Tumilowicz et. $\quad 0-35$ al., 2015

(Guatemala)

Mixed

Method

$(\mathrm{N}=2343)$

6. $\quad$ Horta et. al., $\quad 0-59$ 2013 (Brazil)

Cross sectional $(\mathrm{N}=6075)$
Not mentioned/ Not mentioned

Secondary Stunting

data

(Demographic

and Health

Survey

Data) and

semistructured

interview

Not mentioned/ Guided Stunting

Not mentioned question-naire
Boys are more malnourished as compared to girls, which resulted in a $2.98-\mathrm{cm}$ height-for-age difference (HAD) between sexes in the village and a $1.61-\mathrm{cm}$ HAD $(\mathrm{P}<0.001)$ in the DHS data between 6 and 17 months of age in favor of girls

Factors contributed towards stunting include those children in North region (PR 1.82, 95\%CI 1.20-2.76), female children (PR 0.90, 95\% CI 0.810.99 ), child's age 24-35 months (PR 3.85, 95\%CI 2.65-4.83), no maternal schooling (PR 3.03, 95\%CI 2.22-4.14), no trash collection (PR 1.35, 95\%CI $0.91-2.02$ ), birthweight $<2.5 \mathrm{~kg}$ (PR 2.87, 95\%CI 2.24-3.66), maternal age 30-39 (PR 0.72, 95\% CI 0.60-0.86) and child hospitalized during the prior 12 months (PR 1.20, 95\% CI 1.03-1.41)

Under-weight Factors contributed towards underweight include those children in North region (PR 2.81, 95\%CI 1.584.95), female children (PR 0.80, 95\% CI 0.66-0.97), child's age 12-23 months (PR 1.82 95\%CI 1.09-3.06), child's age 12-23 (PR 1.82, 95\%CI 1.09-3.06), no maternal schooling (PR 3.28. 95\%CI 1.26-6.13), severe maternal anemia (PR 1.63, 95\%CI 1.27-2.10), no trash collection (PR 1.49, 95\%CI 0.952.25), no piped drinking water ( $P R$ 1.52,95\%CI 0.91-2.54), birthweight $<2.5 \mathrm{~kg}$ (PR 8.35,. 95\%CI 4.56-15.27) and child hospitalized during the prior 12 months (PR 1.55, 95\% CI 1.13-2.12) Stunting was associated with child's age betwen 48-59 (OR 12.1; 95\% CI, $5.6,26.1$ ), dirt floored house (OR 1.6, $95 \%$ CI $1.2,2.2)$, indigenous ethnicity (OR 1.9, 95\% CI 1.3, 2.8), region of residence (OR 2.5, 95\%CI 1.3, 4.7), and community divided not by political party (OR 2.7, 95\% CI 1.4, 5.3)

8. Meshram et. 0-59 Not mentioned/ Questionnaire Under-weight Fac Not mentioned underweight were child's age between 1-3 years old (OR 1.89; 95\% CI 1.72 1.89 ) and $3-5$ years old ( OR $1.77 ; 95 \%$ CI 1.77-2.14) as compared to 0-1 year old; boys (OR 1.94 95\% CI 1.09-1.25, family size more between 5-9 (OR 1.10, 95\% CI 1.02-1.18) and >10 ( OR 1.28, 95\% CI 1.07-1.52), illiterate mothers (OR 1.56, 95\% CI 1.32-1.83) and $1^{\text {st }}$ to $8^{\text {th }}$ class mothers (OR $1.50,95 \%$ CI 


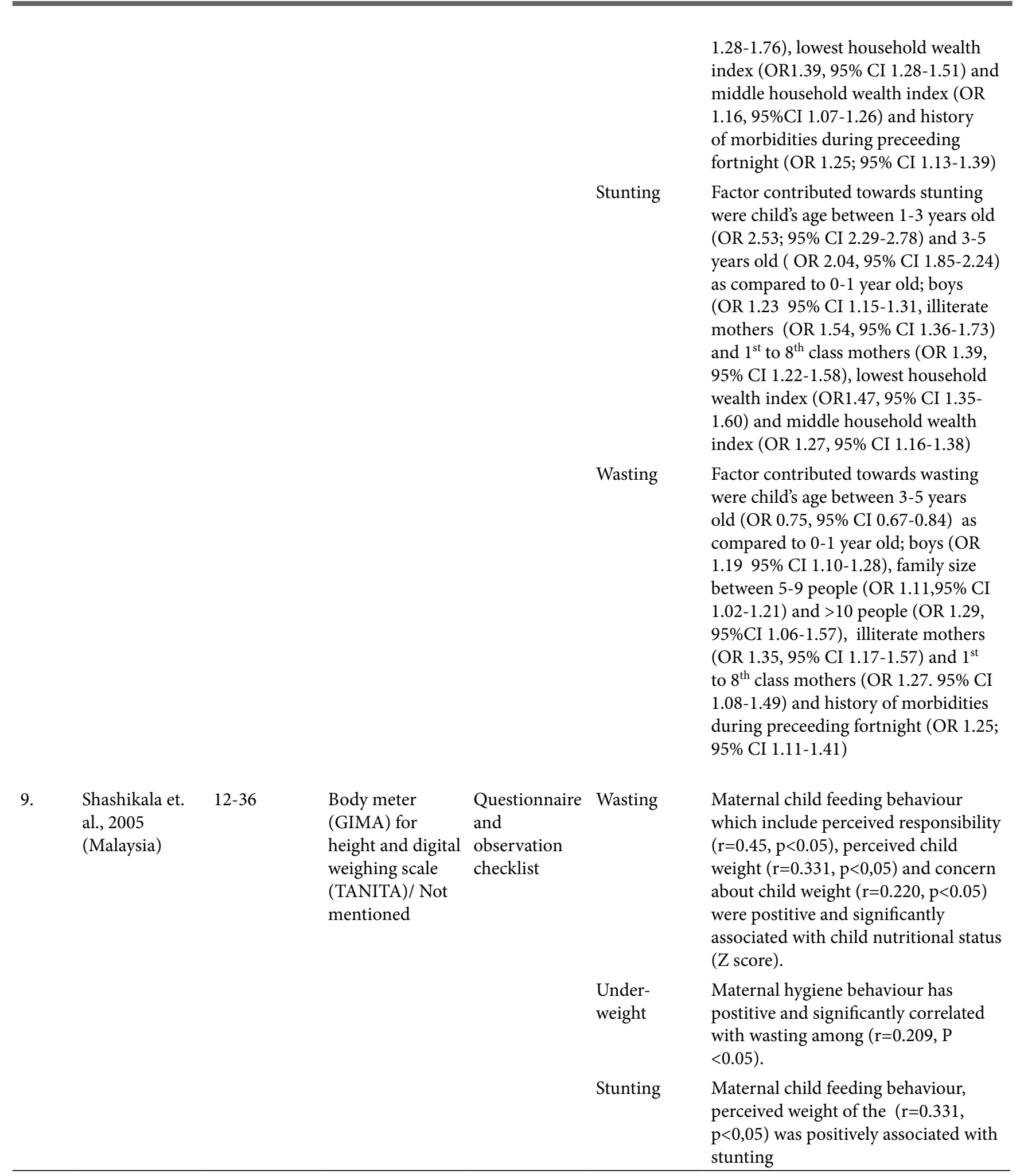

later birth order was known as one of the significant factor increasing risk of malnutrition among indigenous children ${ }^{-}$.

\subsection{Child Morbidity}

A study conducted $\stackrel{2}{2}$ shows that a child history of morbidity during fortnight was more at risk to be wasted as compared to those without history of morbidity during 
Table 3. Factors contributing towards malnutrition according to type of malnutrition among under five indigenous children

\begin{tabular}{|c|c|c|}
\hline Type of malnutrition & Factor & Description \\
\hline \multirow[t]{18}{*}{ Stunting } & 1. Socioeconomic household status & - 1 st tertile of household wealth index ${ }^{1}$ \\
\hline & 2. Household characteristics & $\begin{array}{l}\text { - Region of living }{ }^{9,15} \\
\text { - Living in rural area }{ }^{1} \\
\text { - Living in houses made of walking palm }{ }^{1}\end{array}$ \\
\hline & 3. Child factor & - Sex of the child 92,19 \\
\hline & & - Child's age $\mathrm{e}^{1,9,12,15}$ \\
\hline & & - Later birth order $\underline{14}$ \\
\hline & 4. Parental factor & $\begin{array}{l}\text { - } \text { Birthweight }<2.5 \mathrm{~kg}^{9} \\
\text { - } \quad \text { No maternal schooling } 9\end{array}$ \\
\hline & & - Maternal height $1, \underline{18}$ \\
\hline & & - Maternal education $\frac{12}{2}$ \\
\hline & & - Maternal age between $30-299$ \\
\hline & 5. Indigenous characteristics & - Indigenous ethnicity ${ }^{15}$ \\
\hline & 6. Hygiene & - Use of handwashing agent $t^{14}$ \\
\hline & & - Dirt-floored house $e^{15}$ \\
\hline & & - Cooking location $\underline{14}$ \\
\hline & & - No trash colection ${ }^{9}$ \\
\hline & 7. Feeding behaviour & $\begin{array}{l}\text { - History of introduction of cow's milk before } 30 \text { days of age } \frac{15}{5} \\
\text { - Maternal child feeding behaviour (perceived child weight) })^{16}\end{array}$ \\
\hline & 8. Child morbidity & - Repeated diarrhoeal infection ${ }^{14}$ \\
\hline & & - Hospitalized during the prior 12 months ${ }^{9}$ \\
\hline & 9. Immunisation & - Up to date immunisation ${ }^{1}$ \\
\hline \multirow[t]{13}{*}{ Wasting } & 1. Child factor & - Child's age $\mathrm{e}^{12}$ \\
\hline & & - Sex of the child ${ }^{12}$ \\
\hline & 2. Household factor & $\begin{array}{l}\text { - Medium and high household environment health risk } \\
\text { index } \underline{17}\end{array}$ \\
\hline & 3. Parental factor & - Mothers age ${ }^{17}$ \\
\hline & & - Literacy status household heads $s^{17}$ \\
\hline & & - Maternal literacy status $\underline{\underline{12}}$ \\
\hline & & - Level of exposure to mass media (low, medium and high) $)^{17}$ \\
\hline & 4. Indigenous charateristics & - Scheduled caste households ${ }^{17}$ \\
\hline & 5. Family characteristic & - Family size ${ }^{12}$ \\
\hline & 6. Child morbidity & - History of morbidity during preceeding fortnight $\frac{12}{2}$ \\
\hline & 7. Feeding behaviour & - Colostrum given ${ }^{17}$ \\
\hline & & $\begin{array}{l}\text { - Maternal child feeding behaviour (perceived responsibility, } \\
\text { perceived child weight and concern about child weight) }{ }^{16}\end{array}$ \\
\hline & 8. Immunisation & - Received measles immunisation ${ }^{17}$ \\
\hline \multirow[t]{3}{*}{ Underweight } & 1. Family characteristic & - Family size ${ }^{12}$ \\
\hline & 2. Household characteristic & - Region of living 9 \\
\hline & & - Middle and lowest household wealth index ${ }^{12}$ \\
\hline
\end{tabular}



3. Parental factor
4. Child factor
5. Hygiene
6.Child morbidity
- No maternal schooling 9
- Maternal literacy status $\underline{12}$
- Severe maternal anemia ${ }^{9}$
- Child's age $\mathrm{e}^{9} \underline{12}$
- Sex of the child ${ }^{9}$
- Birthweight $<2.5 \mathrm{~kg}^{9}$
- Maternal hygiene behaviour ${ }^{12}$
- Household without drinking water ${ }^{9}$
- No trash collection ${ }^{2}$
- Hospitalized during the prior 12 months $^{9}$
- History of morbidity during preceeding fortnight $\frac{12}{2}$

fortnight. Similar finding reported 11 which found that who have been hospitalised during the prior 12 months were more likely to be stunted as compared to children without any history of recent illness. An up to date child's immunisation and history of receiving measles vaccination have been shown to give a significant association on stunting and wasting respectively as reported in studies conducted among indigenous children in Brazil and India ${ }^{9,12}$.

Apart from that, a child who was given colostrum was also reported to have significant positive association on nutritional status of the children?

\subsection{Poor Hygiene}

Poor hygiene behaviours such as no usage of hand washing agent, household with no drinking water, no trash collection, dirty floored house and outdoor cooking location were highlighted as part of the contributing factors towards child malnutrition $, \underline{7,}, \underline{13}, \underline{14}$. Such behaviour are related to maternal hygiene behaviour as they are the main caregivers to the children ${ }^{15}$.

\subsection{Feeding Behaviour}

A study conducted in Brazil shows that introduction of cow's milk with 30 days of birth was significantly associated with stunting after adjusting for age, gender and indigenous descent $\frac{12}{}$. Moreover, maternal child feeding behaviour for perceived weight of the child was significant and positively associated with stunting and wasting $\frac{15}{}$.

\subsection{Indigenous Characteristics}

Indigenous characteristics such as indigenous ethnicity, region of residence and intracommunity division has been shown to be significantly associated with malnutrition ${ }^{14}$. Similarly, this was also found in a study conducted in Northeast India, which reported that scheduled tribe household has significant role in lowering risk for wasting among indigenous children?

\subsection{Other: Family Factor}

A study conducted ${ }^{7}$ has reported that family size play an important role in determining child malnutrition. The study revealed highlighted that having more than 5 people in the house increased risk of wasting among indigenous.

\section{Discussion}

Child malnutrition among indigenous population is an important public health problem in developed and developing countries. It does not only touch on the economic aspects but it also significantly affecting health, education, employment, human rights, the environment and more ${ }^{10}$.

It is caused by multidimensional and complex factor which consequently resulting in high morbidity and mortality among the affected children. This review found that socioeconomic status; indigenous characteristic, parental factor, child factor, poor hygiene and child morbidity are among the most common factors contributing towards malnutrition among fewer than five indigenous children found in each type of malnutrition (stunting, wasting and underweight).

Socioeconomic factors such as household wealth index and household characteristics were found as the most significant factors in determining all types of malnutrition among children. As reported by United Nation, indigenous population make up one-third of 
the worlds poorest and suffer alarming conditions in all countries. Poverty is closely related to malnutrition as it is may affect human basic needs such as affordability of buying quality foods and insufficient food intake, household with proper sanitation and supply of good quality of water, access to basic health care as well as education. Moreover, poverty is also part of vicious cycle which includes malnutrition and diseases. Thus, socioeconomics and political changes are strongly needed as part of nutrition and health intervention in order to break the cycle.

Poor hygiene which include personal, environmental and food hygiene was also found as one of the important factor contributing towards malnutrition among indigenous children. Relationship between infectious diseases mainly due to poor hygiene and malnutrition creates a non-ending vicious cycle as malnutrition growth faltering and weight loss with associated micronutrient deficiencies or vice versa. Hygiene practice is one of the five components listed under childcare in the underlying causes of child malnutrition ${ }^{\frac{18}{1}}$. It is regards as part of responsibility of child's primary caregiver (mothers, siblings, fathers and child care providers) by practising proper personal and home hygiene to reduce risk of common childhood infectious diseases for children's healthy growth and development $\frac{19}{}$. Hence, an effective health education to increase caregiver's awareness on the importance of hygiene practice to become part of daily behaviour is essential to tackle malnutrition among children through disease prevention.

Apart from that, parental factor such as young age, education background and maternal feeding behaviour strongly affected child's nutritional status. Parents are considered as the main individuals in charge for food choices of children by playing the role of providers, executors and models for child nutrition at the early stages of childhood ${ }^{20}$.

This review found that maternal feeding behaviour such as early introduction of formula milk and no colostrum given at birth significantly affect child's growth ${ }^{9,12}$. According to a study conducted ${ }^{15}$, most mothers generally perceived child feeding is their responsibility and most of them were concerned about their child maintaining desirable weight. However, similar study also shown that, most mothers did not practice dietary intake restrictions and pressure to eat among their children despite being concern about their growth ${ }^{15}$. Other than having adequate knowledge and attitude among mothers in regards to their maternal feeding behaviour, this is also largely depending on adequate resources or at least absent of constraints to child care for the mothers or caregiver to put their knowledge into practice ${ }^{1}$.

This review also found that younger mothers are more likely to have malnourished children. Children of adolescent mothers are also often at greater risk of poor nutritional care and feeding practices probably due to economic constraints and poor childcare knowledge and experience ${ }^{1}$.

Educated mothers are more likely to be more assertive and to play a greater part in intra-family decision making in favour of their children's needs ${ }^{21}$. Low education and socioeconomic status both may consequently result in poor hygiene, sanitation leading to increase in child morbidity.

Studies have shown that risk of malnutrition increases among children aged between 1-5 years old as compared to less than 1 year old $\stackrel{13}{7}, 14$. Such increments in the prevalent of malnutrition can be due to poor environmental factor as well as weaning practice ${ }^{13}$. In terms of sex of the child, it was noted that boys are more likely to be malnourished as compared to girls. Early introduction of complementary food to boys due to mother's perception that boys are hungrier lead to a vicious cycle of less breast milk and more hunger as well as exposing the boys to pathogens and illnesses $\underline{13}, \underline{23}, \underline{24}$.

Although time frames of the studies have been widened between 2000 until 2017, limited numbers of studies were conducted involving fewer than five indigenous children. Due to limited number of study found, results of the findings have been widened to include correlation, significant factor associated and predictors of malnutrition. In addition, most of the studies included in this review may have a wide range of different political, economy and social background which may contribute towards child malnutrition. Hence, it is evidence that there is a need for more research to be done to explore the factors contributing towards malnutrition among less than five indigenous problems. Furthermore, only studies provided with predictors should be included in the review such as protective and risk factors to strengthen quality of the findings. 


\section{Conclusion}

This review provides a basic understanding of factors contributed towards child malnutrition among indigenous children. It was shown that malnutrition is rarely caused by a single factor, but rather a set of factors linked together leading to a given context. These evidences is essential to plan, develop and implement health intervention that is suitable and appropriate to reduce malnutrition status among under five children specifically for indigenous group. Identification of appropriate and relevant factors contributing towards malnutrition problem among less than five indigenous populations is important to develop a well-planned and ensuring the effectiveness of health intervention.

\section{Reference}

1. Maternal and Child Under-nutrition Study Group: Maternal and child under-nutrition 1 - Maternal and child under-nutrition: Global and regional exposures and health consequences. Date accessed: 17/01/2008. https:/www. thelancet.com/article/S0140-6736(07)61690-0/abstract.

2. Levels and Trends in Child Malnutrition. United Nations International Children's Emergency Fund (UNICEF)1 2018. p. 1-16.

3. Diaz A, Arana A, Vargas-Machuca R, Antiporta D. Health and nutrition of indigenous and nonindigenous children in the Peruvian Amazon/Situacion de salud y nutricion de ninos indigenas y ninos no indigenas de la Amazonia peruana, Revista Panamericana de Salud Publica. 2015; 38(1):49-57. PMid: 26506321.

4. State of the World's Indigenous Peoples. Press Release - State of the World's Indigenous Peoples. Date accessed: 2010. https://www.un.org/development/desa/ indigenouspeoples/publications/state-of-the-worldsindigenous-peoples.html.

5. Inter-Agency Support Group (IASG). Date accessed: 2014. https:/www.un.org/development/desa/indigenouspeoples/ about-us/inter-agency-support-group.html.

6. Indigenous people, Indigenous voices. Date accessed: 2017. https://www.un.org/esa/socdev/unpfii/documents/5session_ factsheet1.pdf.

7. Meshram II, Arlappa N, Balakrishna N, Rao KM, Laxmaiah A, Brahmam GN. Trends in the prevalence of undernutrition, nutrient and food intake and predictors of undernutrition among under five year tribal children in India, Asia Pacific Journal of Clinical Nutrition. 2012; 21(4):568-76. PMid: 23017315.

8. Saxton J, Rath S, Nair N, Gope R, Mahapatra R, Tripathy P, Prost A. Hand washing, sanitation and family planning practices are the strongest underlying determinants of child stunting in rural indigenous communities of Jharkhand and Odisha, Eastern India: A cross sectional study, Maternal and Child Nutrition. 2016; 12(4):869-84. https://doi.org/10.1111/mcn.12323. PMid: 27350365, PMCid: PMC5053246.

9. Singh KD, Alagarajan M, Ladusingh L. What explains child malnutrition of indigenous people of Northeast India? PloS One. 2015; 10(6):130-567.

10. Solomons NW, Vossenaar M, Chomat AM, Doak CM, Koski $\mathrm{KG}$, Scott ME. Stunting at birth: recognition of early-life linear growth failure in the western highlands of Guatemala, Public Health Nutrition. 2015; 18(10):1737-45. https://doi. org/10.1017/S136898001400264X. PMid: 26017476.

11. Tumilowicz A, Habicht JP, Pelto G, Pelletier DL. Gender perceptions predict sex differences in growth patterns of indigenous Guatemalan infants and young children-3, The American Journal of Clinical Nutrition. 2015; 102(5):1249-58. https://doi.org/10.3945/ajcn.114.100776. PMid: 26423387.

12. Araújo TS, Oliveira CS, Muniz PT, Silva-Nunes MD, Cardoso MA. Child undernutrition in one of the cities with greater nutritional risk in Brazil: Population-based study in the Western Brazilian Amazon, Revista Brasileira de Epidemiologia. 2016; 19(3):554-66.

13. Horta BL, Santos RV, Welch JR, Cardoso AM, dos Santos JV, Assis AM, Lira PC, Coimbra Jr CE. Nutritional status of indigenous children: Findings from the First National Survey of Indigenous People's Health and Nutrition in Brazil, International Journal for Equity in Health. 2013; 12(1):1-23. https://doi.org/10.1186/1475-9276-12-23. PMid: 23552397, PMCid: PMC3637628.

14. Sánchez-Pérez HJ, Hernán MA, Ríos-González A, AranaCede-o M, Navarro A, Ford D, Micek MA, Brentlinger P. Malnutrition among children younger than 5 yearsold in conflict zones of Chiapas, Mexico, American Journal of Public Health. 2007; 97(2):229-32. https:// doi.org/10.2105/AJPH.2005.070409. PMid: 17194868, PMCid: PMC1781381.

15. Shashikala S, Kandiah M, Zalilah MS, Khor GL. Nutritional status of 1-3-year-old children and maternal care behaviours in the Orang Asli of Malaysia, South African Journal of Clinical Nutrition. 2005; 18(2):173-80. https:// doi.org/10.1080/16070658.2005.11734061. 
16. Filmer D, Pritchett LH. Estimating wealth effects without expenditure data-or tears: an application to educational enrollments in states of India, Demography. 2001; 38(1):115-32. https://doi.org/10.2307/3088292, https:// doi.org/10.1353/dem.2001.0003 PMid: 11227840.

17. Martines JC, HabichtJP, AshworthA, KirkwoodBR. Weaning in southern Brazil: Is there a "weaning's dilemma"? The Journal of Nutrition. 1994; 124(8):1189-98. https://doi. org/10.1093/jn/124.8.1189. PMid: 8064369.

18. Improving Child Nutrition. The achievable imperative for global progress. United Nations International Children's Emergency Fund (UNICEF); 2013. p. 1-132.

19. The importance of child-caregiver interactions for the survival and healthy development of young children. Date accessed: 2004. https://apps.who.int/iris/ handle/10665/42878.

20. McCaffree J. Childhood eating patterns: The roles parents play, Journal of the American Dietetic Association. 2003; 103(12):1-1587.
21. Christian P, Abbi R, Gujral S, Gopaldas T. The role of maternal literacy and nutrition knowledge in determining children's nutritional status, Food and Nutrition Bulletin. 1988; 10(4):35-40. https://doi. org/10.1177/156482658801000420.

22. Rivera JA, Monterrubio EA, González-Cossío T, GarcíaFeregrino R, García-Guerra A, Sepúlveda-Amor J. Nutritional status of indigenous children younger than five years of age in Mexico: Results of a national probabilistic survey, Salud Pública de México. 2003; 45:466-76. https://doi.org/10.1590/S0036-36342003001000003.

23. Complementary feeding of young children in developing countries: A review of current scientific knowledge. Date accessed: 1998. https://apps.who.int/iris/ handle/10665/65932.

24. Bailey W. Malnutrition among babies born to adolescent mothers, West Indian Medical Journal. 1981; 30(2):72-76. PMid: 7196115. 